\title{
Optimizing irrigation management for pollution control and sustainable crop yield
}

\author{
Ghassan R. Musharrafieh and Richard C. Peralta \\ Department of Biological and Irrigation Engineering, Utah State University, Logan
}

Lynn M. Dudley and Ronald J. Hanks

Department of Plants, Soils, and Biometeorology, Utah State University, Logan

\begin{abstract}
Irrigation strategies which maximize crop yield while preventing salt from leaching to the groundwater or undesirable salt increases in the root zone are computed by using a one-dimensional simulation/optimization management model. The included constraint equations maintain a water volume balance and salt transport in the unsaturated zone. Implicit finite difference forms of the unsaturated water flow equation (Richards' equation), the diffusion-convection solute transport equation, functions describing the hydraulic properties of the medium, a root extraction function, and other constraints are used. The model uses a large discretization in time. A cyclic prediction and correction type of approach is adopted to eliminate the inaccuracy that would otherwise result from the coarse discretization. As a result of the procedure presented, intercell water and mass flux rates in the optimization model have the same accuracy as those in a more finely discretized simulation model. The model is applied to a research farm in Huntington, Utah, where salty water is used for irrigation. In that process detailed soil water and salt profiles are computed and spatially distributed moisture content and concentration constraints are satisfied.
\end{abstract}

\section{Introduction}

Proper management strategies for salinity control require good understanding of the dynamics of water flow and salt transport in the unsaturated zone. Many mathematical models describing unsaturated water flow have been cited in the literature. These include both analytical [Braester, 1973] and numerical [Ross, 1990; Ross and Bristow, 1990; Bresler and Hanks, 1969] approaches. Numerical models simultaneously simulating water flow and solute transport in the vadose zone include those by Bresler and Hanks [1969], Childs and Hanks [1975], Bresler [1973], Hanks and Cui [1991], and van Genuchten [1987].

Numerical simulation of water flow and solute transport in the root zone requires knowledge of soil hydraulic properties and water uptake by plants. Van Genuchten and Nielsen [1985], Campbell [1974], Hutson and Cass [1987], and Brooks and Corey [1964] describe soil hydraulic properties by analytical functions. Functions describing water uptake by plant roots have been reported by Molz [1981], Feddes et al. [1974], Neuman et al. [1975], Bresler et al. [1982], Nimah and Hanks [1973], Feddes et al. [1978], Cardon and Letey [1992a, b], and van Genuchten [1987].

Applying simulation models to develop water management strategies requires repetitive trial and error simulations. On the other hand, simulation/optimization $(\mathrm{S} / \mathrm{O})$ models identify the best operational policies for a given set of objectives and constraints. The trade-offs between objectives and constraints are also determined as a result of the optimization process.

$\mathrm{S} / \mathrm{O}$ models addressing saturated zone groundwater and Copyright 1995 by the American Geophysical Union.

Paper number 94WR02896. 0043-1397/95/94WR-02896\$05.00 groundwater contaminant management include those by Willis [1979], Willis and Yeh [1987], Gorelick [1983], Ahlfeld et al. [1986], Gorelick et al. [1984], Alley [1986], Datta and Peralta [1986], and Gharbi and Peralta [1994]. These include explicit expressions for solute transport in the saturated zone.

Gorelick [1983] and Willis and Yeh [1987] reviewed published methods for representing or controlling solute transport or groundwater concentrations within optimization models. Both response matrix and embedding methods have been used to manage groundwater contamination.

Gradient or contaminant velocity control is used to restrict transport and control contaminant migration in linear and nonlinear S/O models [Molz and Bell, 1977; Remson and Gorelick, 1980; Heidari et al., 1982; Colarullo et al., 1984; Atwood and Gorelick, 1985; Peralta and Ward, 1991]. This approach may be inappropriate if some. advective transport through control location is acceptable.

$\mathrm{S} / \mathrm{O}$ models maximizing irrigation water delivered, crop yield, or economic return resulting from irrigation are frequently cited in the literature [Yaron and Harpinist, 1980; Khan, 1982; Bowen and Young, 1985]. In these, a single-layer root zone is modeled, and salt concentration is calculated on a volume balance basis. Yaron and Harpinist [1980] developed a dynamic programming model for optimal irrigation scheduling with water of various salinity levels. Matanga and Marino [1979] developed an interseasonal stochastic dynamic model that maximizes the gross marginal income from a crop over a finite and infinite planning horizon. The salinity transform function that they used is based on a mass balance approach.

Conjunctive use S/O models that consider groundwater flow, stream aquifer interflow, water use decisions, and agronomic relationships between crop production and the depth of applied irrigation water include those by Peralta et al. [1988a], 
Lefkoff and Gorelick [1990], and Peralta et al. [1990]. Of these, the most detailed of the vadose zone processes involves modeling a single-layer root zone. Salt concentration is calculated based on a volume balance basis, without a spatially detailed description of vertical system dynamics.

An S/O model which can determine an optimal irrigation strategy that will maximize crop yield while preventing groundwater contamination is needed. The S/O model should be accurate and able to address the dynamics of the unsaturated zone in detail. Such a model will be useful for planning sustainable agricultural production.

The S/O model presented here includes the simulation approach of SOWATSAL [Hanks and Cui, 1991] for water flow and solute transport in the vadose zone. The ability of SOWATSAL to describe accurately water flow and salt transport in the vadose zone has been tested and verified in many parts of Utah. It has proven to be reliable and accurate when compared with field data. Here, SOWATSAL is modified with a root extraction term adopted from van Genuchten [1987]. The resulting code is termed mod-SOWATSAL and is a part (module) of the S/O model. Functional equivalents of modSOWATSAL are embedded as constraint equations within optimization modules of the $\mathrm{S} / \mathrm{O}$ model. The $\mathrm{S} / \mathrm{O}$ model is applied to a single irrigation season. In the $\mathrm{S} / \mathrm{O}$ model, irrigation timing is known a priori, but the amount applied is a decision variable computed by the model.

\section{Model Formulation}

The model presented addresses the following management objectives: (1) maximize crop yield while preventing salt from reaching the groundwater and (2) maximize crop yield while ensuring that salt concentrations in the root zone do not exceed specified values.

The simulation/optimization procedure includes data and known parameter input and simulation and optimization processes. Input data include potential evapotranspiration $\left(E T^{p}\right)$, soil water content at saturation, saturated hydraulic conductivity, bubbling pressure, root density function, and initial and boundary conditions. For the simulation and optimization processes, processing involves solving the $\mathrm{S} / \mathrm{O}$ problem to compute an irrigation strategy that maximizes crop yield subject to the imposed constraints. Constraints vary with management scenarios. The $\mathrm{S} / \mathrm{O}$ model solves all equations (for all time steps) simultaneously in time and space. Therefore it cannot use as fine a discretization in time as a normal simulation module, which solves for only one time step at a time. If not compensated for, this coarseness could cause water and salt profiles calculated by the S/O model to be inaccurate (compared with those calculated by the simulation module). To overcome this problem, a cyclical prediction and correction approach is used within the S/O model. This avoids numeric errors which could result from the discretization used.

The cyclical approach used is similar to that presented by Peralta et al. [1988b] for optimizing saturated zone contaminant management. Their proposed procedure (MODCON, Model for Modifying Contaminant Concentration) includes calibrating the solute transport equations of an optimization module to achieve the same solute transport predicted via a more detailed simulation module. They used goal programming to calibrate the optimization module's finite difference advective transport equations, so that the equations predict the same concentrations as a more accurate method of character-

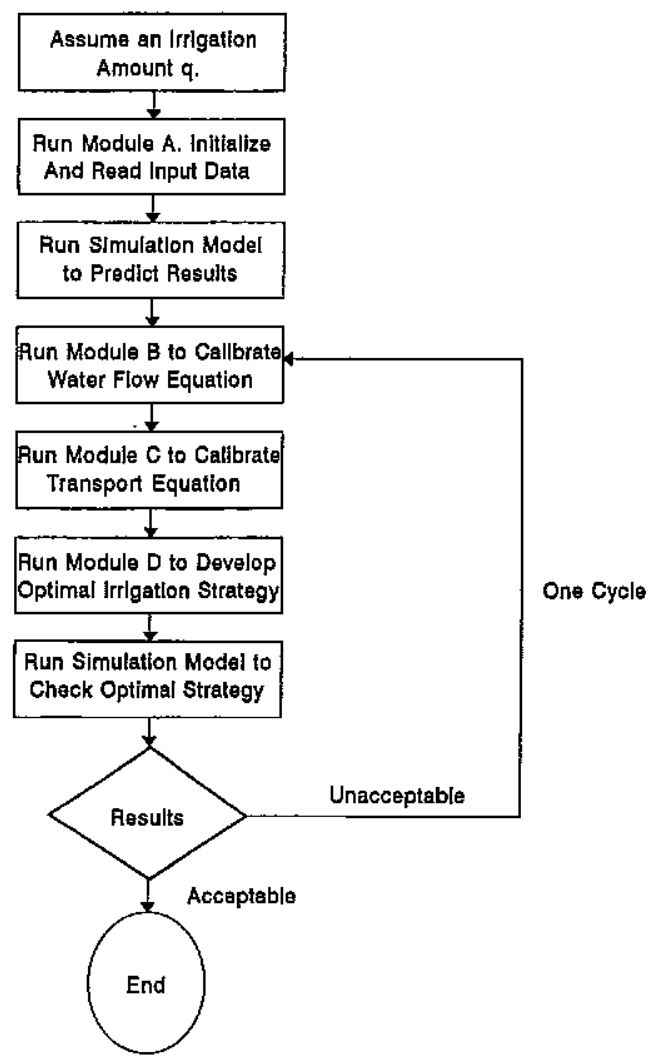

Figure 1. Solution mechanism and cycling.

istics simulation module. Changes in concentration due to dispersion, as computed by the simulation module, were used directly in the optimization module. The same general approach is applied here. However here, both water flow and advective solute transport finite difference approximations are calibrated for use in the $\mathrm{S} / \mathrm{O}$ model.

To implement this approach for a system of $I$ cells $(i=$ $1, \cdots, I)$ and a planning horizon of $j$ time steps $(j=1, \cdots$, $J$ ), the S/O model is partitioned into four modules, A through $D$, which are solved sequentially and repetitively in a cyclical process (Figure 1). These modules, and an external simulation module (mod-SOWATSAL), are linked together. Module D calculates the optimal irrigation strategy using results from modules $\mathrm{A}-\mathrm{C}$ and the external simulation module. Module $\mathrm{A}$ reads input data. Modules B and C utilize optimization to calculate calibration parameters for application to the finite difference approximations of the water flow and transport equations, respectively. The simulation module (modSOWATSAL) computes soil moisture and salt concentrations at two locations within the flow process (Figure 1).

The cyclical solution process is explained in a subsequent solution algorithm discussion. The function of each module is described below.

\subsection{Module A}

Module $\mathrm{A}$ is an initialization module. It prepares input data and calculates parameters. It computes potential transpiration and potential soil evaporation from input potential evapotranspiration following the procedure presented by Hanks and Cui [1991]. It initializes the root density function, sets the time step size, and requests the input data file containing the initial and boundary conditions. 


\subsection{Module B}

Module B calibrates the finite difference form of the water flow equation to predict soil moisture profiles that match those computed by the simulation module, which uses a finer discretization in time. Module B uses nonlinear goal programming. The objective function is linear but the constraints are nonlinear.

In goal programming, the decision maker specifies a set of goals or targets for each objective. Here, the goal programming S/O model identifies the management plan that minimizes the sum of differences between achieved values of state variables and specified target values. In module $\mathrm{B}$, target values are matric potential values obtained from the external simulation module $\left(\Psi_{i}^{T j}\right)$. The module B objective function (equation (1)) minimizes the sum of overachievement and underachievement values ( $\Psi_{i}^{o j}$ and $\Psi_{i}^{u j}$, respectively) from these target values. $\Psi_{i}^{o j}$ is the amount by which the $S / O$ model overestimates the value of the matric potential computed by the simulation module. $\Psi_{i}^{u j}$ is the amount by which the S/O model underestimates the value of the matric potential compared with the simulation module. For any cell, one achievement variable value will be 0 . The other can be 0 (if there is no difference between values predicted by the $\mathrm{S} / \mathrm{O}$ and the simulation module) or a positive value. For example, if $\Psi_{i}^{o j}$ is 1 and $\Psi_{i}^{u j}$ is 0 , the S/O value is one unit greater than the simulated value. If $\Psi_{i}^{u j}$ is 1 and $\Psi_{i}^{o j}$ is 0 , the S/O model value is one unit less than the simulation module value. In module $\mathrm{B}$, both overachievement and underachievement values are equally important. This means that neither overachievement nor underachievement is preferred.

$$
\min Z Z=\sum_{i=1}^{i=I} \sum_{j=1}^{j=I}\left(\Psi_{i}^{o j}+\dot{\Psi}_{i}^{u j}\right)
$$

Equation (2) relates water flux (evaporation or infiltration) at the soil surface to matric potential. Water flux is assimed to be known and is the same as results from the previous run of the external simulation module. Equation (3) represents the fully implicit finite difference form of transient water flow in a vertical soil column [Hanks and Cui, 1991]. In (3), dimensionless weighting coefficients $\left(f_{i}^{j}\right)$ are applied to matric potentials to correct for the inappropriate gradient between adjacent cells caused by the coarse discretization in time. This correction will cause module B predictions to match those predicted by the simulation module (mod-SOWATSAL), which uses finer discretization in time. Here; $\Psi_{i}^{i}$ is matric potential $(L)$, $C a_{i}^{j}$ is the specific water capacity $\left(L^{-1}\right), A_{i}^{j}$ is a root extraction function $\left(T^{-1}\right)$, and $K_{i}^{j}$ is the soil hydraulic conductivity $\left(L T^{-1}\right)$. In the sign convention adopted here, fluxes are positive for downward flow (infiltration) and negative for upward flow (evaporation).

$$
\begin{gathered}
q_{i}^{j}=\frac{K_{i+1 / 2}^{j}\left(f_{i}^{j} \Psi_{i}^{j}-f_{i+1}^{j} \Psi_{i+1}^{j}+\Delta z_{1}\right)}{\Delta z_{1}} \quad i=1 \\
\frac{f_{i}^{j} \Psi_{i}^{j}-f_{i}^{j-1} \Psi_{i}^{j-1}}{\Delta t}=K_{i-1 / 2}^{j} \frac{f_{i-1}^{j} \Psi_{i-1}^{j}-f_{i}^{j} \Psi_{i}^{j}+\Delta z_{1}}{\Delta z_{1} \Delta z_{3} C a_{i}^{j}} \\
-K_{i+1 / 2}^{j} \frac{f_{i}^{j} \Psi_{i}^{j}-f_{i+1}^{j} \Psi_{i+1}^{j}+\Delta z_{2}}{\Delta z_{2} \Delta z_{3} C a_{i}^{j}}+A_{i}^{j} \quad i>1
\end{gathered}
$$

Equation (4) represents analytical expressions relating hydraulic conductivity to matric potential [Brooks and Corey,
1964]. These apply when $\Psi_{i}^{j}<\Psi_{b}$ (bubbling pressure). If $\Psi_{i}^{j} \geq \Psi_{b}$, then $K_{i}^{j}$ equals $K_{s}$ (saturated hydraulic conductivity).

$$
K_{i}^{j}=K_{s}\left(\frac{\Psi_{b}}{\Psi_{i}^{j}}\right)^{\beta}
$$

The goal programming constraint, equation (5), uses overachievement and underachievement variables to relate the matric potential calculated by the $\mathrm{S} / \mathrm{O}$ model with that calculated by the simulation module. Equation (6) limits the values of $f$ coefficients to be within upper and lower bounds. Usually these coefficients are computed as being different from 1. Equation (7) limits overachievement and underachievement values to be greater than 0 .

$$
\begin{gathered}
\Psi_{i}^{j}+\Psi_{i}^{u j}-\Psi_{i}^{o j}=\Psi_{i}^{T j} \\
0 \leq f_{i}^{j} \leq f_{i}^{u j} \\
0 \leq \Psi_{i}^{u j}, \Psi_{i}^{o j}
\end{gathered}
$$

Equations (1)-(7) are solved simultaneously in time and space. Variables in module $\mathbf{B}$ include matric potential overachievement and underachievement values, computed matric potential values, calibration coefficients, and soil hydraulic conductivity. Knowns in module B include target matric potential values, water extraction by roots, and irrigation amount as computed by the external simulation module.

\subsection{Module $\mathrm{C}$}

Module $\mathrm{C}$ calibrates the finite difference form of the transport equation for salt flow in the unsaturated zone against the external simulation module (mod-SOWA'ISAL), so that concentrations predicted by the optimization module and the simulation module ате the same. Module $C$ uses a goal programming approach that minimizes the sum of overachievement and underachievement variables for concentration $\left(C_{i}^{o j}\right.$ and $C_{i}^{u j}$ in (8)). These variables represent the difference between concentration predicted by the $S / O$ model $\left(C_{i}^{j}\right.$ of (11), discussed later) and that estimated by mod-SOWATSAL $\left(C_{i}^{T j}\right.$ of (11)).

$$
\min Z=\sum_{i=1}^{i=I} \sum_{j=1}^{j=J}\left(C_{i}^{o j}+C_{i}^{u j}\right)
$$

The fully implicit finite difference form of the convectiondispersion equation is represented by (9) [Bresler, 1973]. The $c f_{i}^{j}$ coefficients applied to the equation serve the same purpose as the $f_{i}^{j}$ coefficients applied to the water flow equation. In the equation, $D D_{i}^{j}$ is the dispersion term $\left(L^{2} T^{-1}\right), C_{i}^{j}$ is salt concentration (milliequivalents per liter), and $q_{i}^{j}$ is water flux $\left(L T^{-1}\right)$.

$$
\begin{gathered}
\frac{\theta_{i}^{j} C_{i}^{j}-\theta_{i}^{j-1} C_{i}^{j-1}}{\Delta t}=D D_{i-1}^{j} \frac{C_{i-1}^{j}-C_{i}^{j}}{\Delta z_{1} \Delta z_{3}}-D D_{i}^{j} \frac{C_{i}^{j}-C_{i+1}^{j}}{\Delta z_{2} \Delta z_{3}} \\
-\frac{c f_{i}^{j} q_{i}^{j} C_{i}^{j}-c f_{i-1}^{j} q_{i-1}^{j} C_{i-1}^{j}}{\Delta z_{3}}
\end{gathered}
$$

Equation (10) relates volumetric water content to matric potential. Module $\mathrm{C}$ computes concentrations for each cell in the subsystem. Values of matric potential computed by module $\mathrm{B}$ are used to compute volumetric moisture content within module C. The water fluxes (velocities) and hydraulic conduc- 
tivity values used in module $C$ are those computed by module B. The calibration coefficients $\left(c f_{i}^{j}\right)$ and salt concentrations $C_{i}^{j}$ in module $\mathrm{C}$ are initially unknown. This causes module $\mathrm{C}$ to have nonlinear constraints but a linear objective function. Changes in concentrations due to dispersion $\left(D D_{i}^{j}\right)$ as computed by the simulation module are used directly in modules $C$ and $D$. A mass balance is maintained within the equation since the same coefficient $c f$ is applied to both sides of a particular intercell boundary (the goal programming constraint, (11), relates salt concentration calculated by the S/O model with that calculated by the simulation model). As with the $f$ coefficients in module $\mathrm{B}$, the $c f$ coefficient values are limited by upper and lower bounds (equation (12)). The concentration achievement variables are also bounded to be nonnegative (equation (13)).

$$
\begin{gathered}
\theta_{i}^{j}=\theta_{s}\left(\frac{\Psi_{b}}{\Psi_{i}^{j}}\right)^{\alpha}+\theta^{o} \\
C_{i}^{j}+C_{i}^{u j}-C_{i}^{o j}=C_{i}^{T j} \\
0 \leq c f_{i}^{j} \leq c f_{i}^{u j} \\
0 \leq C_{i}^{o j}, C_{i}^{u j}
\end{gathered}
$$

In summary, salt concentrations $\left(C_{i}^{j}\right)$, overachievement and underachievement values on salt concentration $\left(C_{i}^{o j}\right.$ and $C_{i}^{u j}$, respectively), and calibration coefficients $\left(c f_{i}^{j}\right)$ are variables computed by module $\mathrm{C}$. Knowns in module $\mathrm{C}$ include irrigation amount, water fluxes, and matric potential values $\left(q_{i}^{j}\right.$ and $\Psi_{i}^{j}$, computed by module B), dispersion coefficients $\left(D D_{i}^{j}\right.$, computed by the external simulation module), volumetric moisture content $\left(\theta_{i}^{j}\right)$, and target salt concentration values $\left(C_{i}^{T j}\right)$.

\subsection{Module D}

Module $D$ contains all equations from modules $B$ and $C$ with calculated calibration coefficients, $f$ and $c f$, as well as some additional constraints. The decision variable in module $D$ is the irrigation amount. Target concentrations and head values are not the results of previous simulations. These values are set by management objectives. Matric potential, salt concentration, volumetric water content, water extraction by roots (a function of salt concentration and matric potential), soil hydraulic conductivity, and water fluxes (a function of matric potential) are variables computed by module $\mathrm{D}$. The calibration coefficients applied to the water flow and transport equations are knowns in module D (computed in modules B and C). Module D calculates the irrigation strategy ( $q$, values, decision variable) that maximizes crop yield while satisfying imposed constraints. By performing optimizations with different sets of constraints, the user can determine the trade-offs between maximizing production and avoiding undesirable salt leaching.

The objective function in module $\mathrm{D}$ maximizes crop yield. Yield is estimated based on the concept developed by De Wit [1958] and improved by Hanks et al. [1969], R. J. Hanks (unpublished data, 1975), and Hanks [1983]. R. J. Hanks (unpublished data, 1975) defined the relation between yield and transpiration as

$$
\frac{Y^{a}}{Y^{p}}=\frac{\sum_{i=1}^{I} \sum_{j=1}^{J}\left(A_{i}^{j} \Delta t \Delta x\right)}{\sum_{j=1}^{J} T_{j}^{p}}
$$

The objective function is

$$
\begin{aligned}
\min T= & \sum_{i=1}^{I} \sum_{j=1}^{J}\left(A_{i}^{j} \Delta \dot{t} \Delta x\left(1-R_{d p}\right)+w_{c}^{+} C_{i}^{o j}+w_{m}^{+} \Psi_{i}^{o j}\right. \\
& \left.+w_{c}^{-} C_{i}^{u j}+w_{m}^{-} \Psi_{i}^{u j}\right)
\end{aligned}
$$

where $Y$ is dry matter yield $\left(M L^{-2}\right)$, superscripts $a$ and $p$ represent actual and potential conditions, respectively, $T_{j}^{p}$ is potential transpiration $\left(L T^{-1}\right)$, and $T$ is total actual transpiration $(L)$. From (14), maximizing actual transpiration maximizes yield. Because transpiration is negative and overachievement and underachievement values are positive, the objective function (equation (15)) is a minimization (maximizing the absolute value of transpiration and minimizing the absolute values of overachievement and underachievement variables).

The objective function iricludes water transpired by plant roots and overachievement and underachievement variables on head and concentrations with appropriate weights $\left(w_{m}^{-}\right.$, $w_{m}^{+}, w_{c}^{-}$, and $w_{c}^{+}$) applied to them. These overachievement and underachievement values are necessary to ensure that computed values for concentrations and matric potential are as close to management goals as possible: Equation (16) represents boundary conditions at the soil surface for infiltration or evaporation. The top boundary is a flux boundary. The bottom of the soil column is a constant-head/constrained-flux boundary. Although head is specified, flow across that boundary is constrained so as not to exceed specified limits (a bound might be such as to entirely halt flow across the bottom boundary). Salt concentration at the top boundary equals the salt concentration in the irrigation water on an irrigation day. During evaporation there is no salt flow across the top boundary. At the bottom boundary, there is no salt flow if there is no water flow (a negligible amount of salt can still move by diffusion). If there is water flow there can be salt flow.

$$
q_{i}^{j}=\frac{K_{i+1 / 2}^{j}\left(f_{i}^{j} \Psi_{i}^{j}-f_{i+1}^{j} \Psi_{i+1}^{j}+\Delta z_{1}\right)}{\Delta z_{1}} \quad i=1
$$

Equations (17) and (18) are similar to (3) and (9), respectively, except that the calibration coefficients are supplied as knowns to module $\mathrm{D}$, having been calculated in modules $\mathrm{B}$ and C. Equations (19) and (20) are similar to (4) and (10) of modules B and C, respectively. Transpiration (water extraction by plant roots) is calculated via (21) [van Genuchten, 1987]. Here, $\lambda_{i}^{j}$ is a root density function that depends on the maximum length of the roots and vertical distance from the soil surface, $a_{1}$ is a constant, $T^{p}$ is potential transpiration, and $C_{50}$ $(L)$ is the potential at which yield is reduced by $50 \%$. Note that concentration $C_{i}^{j}$ is converted to osmotic potential by multiplying it by $-36(S$, osmotic potential (millibars) $=-360$ meq/10 L [U.S. Salinity Laboratory Staff, 1954]).

$$
\begin{aligned}
& \frac{f_{i}^{j} \Psi_{i}^{j}-f_{i}^{j-1} \Psi_{i}^{j}-1}{\Delta t}= K_{i-1 / 2}^{j} \frac{f_{i-1}^{j} \Psi_{i-1}^{j}-f_{i}^{j} \Psi_{i}^{j}+\Delta z_{1}}{\Delta z_{1} \Delta z_{3} C a_{i}^{j}} \\
&-K_{i+1 / 2}^{j} \frac{f_{i}^{j} \Psi_{i}^{j}-f_{i+1}^{j} \Psi_{i+1}^{j}+\Delta z_{2}}{\Delta z_{2} \Delta z_{3} C a_{i}^{j}}+A_{i}^{j} \\
& \frac{\theta_{i}^{j} C_{i}^{j}-\theta_{i}^{j-1} C_{i}^{j-1}}{\Delta t}= D D_{i-1}^{j} \frac{C_{i-1}^{j}-C_{i}^{j}}{\Delta z_{1} \Delta z_{3}}-D D_{i}^{j} \frac{C_{i}^{j}-C_{i+1}^{j}}{\Delta z_{2} \Delta z_{3}} \\
&-\frac{c f_{i}^{j} q_{i}^{j} C_{i}^{j}-c f_{i-1}^{j} q_{i-1}^{j} C_{i-1}^{j}}{\Delta z_{3}}
\end{aligned}
$$




$$
\begin{gathered}
K_{i}^{j}=K_{s}\left(\frac{\Psi_{b}}{\Psi_{i}^{j}}\right)^{\beta} \\
\theta_{i}^{j}=\theta_{s}\left(\frac{\Psi_{b}}{\Psi_{i}^{j}}\right)^{\alpha}+\theta^{o} \\
A_{i}^{j}=\frac{\lambda_{i}^{j} T^{p}}{1+\left[\left(a_{1} \Psi_{i}^{j}+C_{i}^{j}\right) / C_{50}\right]^{3}}
\end{gathered}
$$

The S/O model considers yield reduction due to deep percolation $\left(R_{d p}\right)$ if desired (equations (22) and (23)) [Doorenbos and Kassam, 1979]. To do this, a deep percolation yield reduction factor $F_{d p}$ is estimated and used as input to the model. This factor depends on the soil characteristics and plant sensitivity to deep percolation and is usually estimated by field experimentation. Here, $D_{r z}$ is depth of root zone $(L), d_{n}$ is root zone maximum water holding capacity $(L)$, and $\theta_{f c}$ and $\theta_{w p}$ are volumetric water content at field capacity and permanent wilting point, respectively. $D_{p}^{j}$ is water percolating below the root zone after an irrigation event $(L)$.

$$
\begin{array}{r}
d_{n}=D_{r z}\left(\theta_{f c}-\theta_{w p}\right) \\
\sum_{j=1}^{J} D_{p}^{j} \\
R_{d p}=F_{d p} \frac{1}{d_{n}}
\end{array}
$$

Equations (24) and (25) are overachievement and underachievement constraints on salt concentration and matric potential, respectively. These constraints are necessary to ensure that computed values for concentrations and matric potential are as close to management goals as possible. Here, the target values are not the results of previous simulations. Target values might be used for all cells and stress periods or for only a few cells. Depending on management goals, either overachievement or underachievement variables or both are minimized in the objective function. The model will try to force these values to 0 to achieve target concentrations or heads. Dimensionless weights $w_{m}^{-}, w_{m}^{+}, w_{c}^{-}$, and $w_{c}^{+}$are applied to overachievement and underachievement values of matric potential and concentration.

$$
\begin{gathered}
C_{i}^{j}-C_{i}^{o j}+C_{i}^{u j}=C_{i}^{m T j} \\
\Psi_{i}^{j}-\Psi_{i}^{o j}+\Psi_{i}^{u j}=\Psi_{i}^{m T j}
\end{gathered}
$$

Bounds on variables are imposed via (26)-(30). The lower and upper bounds on applied water are 0 and maximum available water, respectively. The soil matric potential is bounded between 0 and the matric potential of air dry soil. Volumetric soil moisture is bounded between air dry moisture content and moisture content at saturation. The amount of water transpired by the plant must be between potential transpiration and 0 . Employing bounds on variables means that the computed irrigation strategy will ensure that acceptable values of these variables will result.

$$
\begin{gathered}
0 \leq q_{i}^{j} \leq q^{u} \\
0 \leq C_{i}^{o j}, C_{i}^{u j}, \Psi_{i}^{o j}, \Psi_{i}^{u j} \\
\Psi^{s} \geq \Psi_{i}^{j} \geq \Psi^{a} \\
\theta^{s} \geq \dot{\theta}_{i}^{j} \geq \theta^{a}
\end{gathered}
$$

$$
0 \geq A_{i}^{j} \geq T^{p}
$$

Assumptions made in this model are the same as those assumed by Hanks and Cui [1991] in SOWATSAL: a homogeneous one-dimensional soil column, no hysteresis, and an inert salt.

\section{Solution Algorithm}

The modeling methodology employs cycling to help ensure the accuracy of flow and transport representation during optimization. Cycling is an approach for solving nonlinear optimization schemes [Peralta and Killian, 1985; Gharbi and Peralta, 1994]. Values of the variables, irrigation amount, matric potential, and salt concentration are first assumed. Optimization begins and an optimal solution is computed. A second cycle begins using the optimal values from the first cycle as an initial guess. In essence, this process continues until the optimal strategy cannot be improved upon and assumed values are the same as the optimal values.

In the S/O model, cycling involves five steps (Figure 1 ).

1. Run the simulation module for an initial guess. That is, an irrigation strategy is assumed, and the simulation module is run to calculate the system response to this strategy.

2. Module A is started. Input data are read and parameters are calculated.

3. Module $B$ is invoked to calculate calibration variables so that the matric potential predicted by module $B$ matches those from the simulation module.

4. Module $\mathrm{C}$ is run to generate the necessary coefficients to be applied to the solute transport equation so that concentrations later predicted by module $D$ will be replicated or verified by postoptimization simulation.

5. Optimization is performed in module D. After an optimal irrigation strategy is obtained, it is tested via the simulation module. If the simulation module predicts the same water and salt distribution, the $\mathrm{S} / \mathrm{O}$ model is considered to have converged to a local optimum.

After the five-step cycling process has resulted in convergence to an optimal solution, several other cycling efforts should be conducted. Each begins using an initial guess for the optimal solution that is dramatically different from a previously used initial guess. Because the constraints are nonlinear, these other processes might converge to a different solution, each of which is locally optimal. The best of all computed solutions is used.

\section{Model Application}

The model is applied to a location on the Huntington Research Farm, Huntington, Utah $\left(39^{\circ} 22^{\prime} \mathrm{N} 111^{\circ} 22^{\prime} \mathrm{W}\right)$. Because of low rainfall during the growing season, irrigation is needed for adequate crop yield. Recycled saline water from the Utah Power and Light Company is used. The state of Utah requires that if this salty water is to be used for irrigation, no salt should reach the water table. To be able to use this saline water for irrigation and prevent groundwater contamination, Dudley et al. [1991], Malek et al. [1991], and Bingham et al. [1988, 1989, 1990] have conducted field experiments and determined water budget information for the area.

To determine how to use this saline water for irrigation and preserve groundwater quality, the S/O model was run to achieve the following objectives. 
Table 1a. Optimal Irrigation Strategies and Consequences Computed for Tested Scenarios: Approach A

\begin{tabular}{|c|c|c|c|c|}
\hline \multirow{2}{*}{$\begin{array}{l}\text { Irrigation } \\
\text { Frequency }\end{array}$} & \multirow[b]{2}{*}{ Irrigation Scheme } & \multirow[b]{2}{*}{$\Sigma Q$} & \multicolumn{2}{|c|}{$\begin{array}{l}\text { Yield, \% of } \\
\text { potential }\end{array}$} \\
\hline & & & Optimal & Simulated \\
\hline \multirow[t]{3}{*}{ 7-Day } & constant $Q$ & 1253 & 69.2 & 69.9 \\
\hline & three levels $\left(Q_{1}, Q_{2}, Q_{3}\right)$ & 1368 & 80.3 & 81 \\
\hline & variable $Q$ & 1361 & 81.7 & 82 \\
\hline \multirow[t]{3}{*}{ 10-Day } & constant $Q$ & 1200 & 67.1 & 67.9 \\
\hline & three levels $\left(Q_{1}, Q_{2}, Q_{3}\right)$ & 1336 & 77.4 & 77.2 \\
\hline & variable $Q$ & 1394 & 79.8 & 79.8 \\
\hline
\end{tabular}

Salt deposition in the profile maximized; no salt movement below $212.5 \mathrm{~cm}$.

1. Develop a seasonal optimal irrigation strategy that maximizes crop yield and prevents salt leaching to the groundwater (maximizes salt deposition in the soil profile). This might lead to degradation of salts through chemical reactions for different irrigation schemes.

2. Maximize crop yield while ensuring that salt concentrations in the root zone do not exceed specified values. From these objectives the trade-off between maximizing crop yield and environmental protection will be determined. The tradeoff is the difference between yield obtained when no constraint on salt movement is used versus that when salt leaching is prevented.

To achieve these objectives, two management approaches are considered. Approach A permits no salt leaching. Approach B permits leaching. For approach A, six different scenarios are considered (Table 1a); three scenarios are considered for approach B (Table 1b). Each scenario utilizes a different combination of irrigation frequency and irrigation scheme. Selected are 7- and 10-day frequencies, representing compromises between frequent and infrequent irrigations. For each frequency, up to three schemes of water application are used (Figure 2). The first scheme employs a constant water amount applied on all irrigation days throughout the season; the second allows three different irrigation amounts depending on the time of the season; and the third permits a different amount every irrigation.

The modeled system is a vertical soil column $250 \mathrm{~cm}$ deep and $1 \mathrm{~cm}$ wide. This extends from the ground surface through a $200-\mathrm{cm}$ alfalfa rooting zone. The column is divided into 20 blocks, or cells, each cell being $12.5 \mathrm{~cm}$ in length. The planning period is for one irrigation season (197 days). No intermediate harvesting is assumed.

The time steps used within the optimization model are 1, 3, and 6 days. For a 7-day irrigation frequency, time steps of 1 and

Table 1b. Optimal Irrigation Strategies and Consequences Computed for Tested Scenarios, Approach B

\begin{tabular}{|c|c|c|c|c|}
\hline \multirow{2}{*}{$\begin{array}{l}\text { Irrigation } \\
\text { Frequency }\end{array}$} & \multirow[b]{2}{*}{ Irrigation Scheme } & \multirow[b]{2}{*}{$\Sigma Q$} & \multicolumn{2}{|c|}{$\begin{array}{l}\text { Yield, } \% \text { of } \\
\text { potential }\end{array}$} \\
\hline & & & Optimal & Simulated \\
\hline 7-Day & $\begin{array}{l}\text { three levels }\left(Q_{1}, Q_{2}, Q_{3}\right) \\
\text { variable } Q\end{array}$ & $\begin{array}{l}3934 \\
3530\end{array}$ & $\begin{array}{l}93 \\
92.2\end{array}$ & $\begin{array}{l}92.9 \\
92.4\end{array}$ \\
\hline 10-Day & variable $Q$ & 2146 & 93.4 & 92.9 \\
\hline
\end{tabular}

A target salt concentration in the top $112.5 \mathrm{~cm}$ of $\leq 160 \mathrm{meq} / \mathrm{L}$ is maintained.
6 days are used ( 1 day for irrigation and 6 days between irrigations). For a 10-day irrigation frequency a 1-day time step (for irrigation) is followed by three 3-day time steps (without irrigation). Potential evapotranspiration, rain, and soil hydraulic properties for the 1988 growing season are detailed by Musharrafieh [1993].

Potential evapotranspiration is divided into potential soil evaporation and potential transpiration using a factor of 0.9 [Hanks and Cui, 1991]. Other parameters used in the model are saturated hydraulic conductivity, $K_{s}\left(3.6 \mathrm{~cm} \mathrm{~h}^{-1}\right)$; bubbling pressure, or air entry pressure, $\Psi_{b}(-0.1 \mathrm{~m})$; a constant $a_{1}$ (1); water potential at which yield is reduced by $50 \%, C_{50}$ $(-10,500 \mathrm{~cm})$; exponential constant $\beta(2.448)$; exponential constant $\alpha(0.224)$; air dry moisture content, $\theta^{a}\left(0.02 \mathrm{~cm}^{3}\right.$ $\left.\mathrm{cm}^{-3}\right)$; moisture content at saturation, $\theta_{s}\left(0.4 \mathrm{~cm}^{3} \mathrm{~cm}^{-3}\right)$; and yield reduction due to deep percolation, $R_{d p}(0)$.

Table 2 gives the initial and boundary conditions governing the modeled flow system. At the soil surface, all irrigation water is assumed to infiltrate into the soil without ponding or runoff. The bottom boundary has a water content equal to 0.15 (on a volumetric basis) and a salt concentration of $74 \mathrm{meq} / \mathrm{L}$. These initial conditions are obtained from measured field data for the 1988 growing season and apply to both the external simulation module and the S/O models.

For approach $\mathrm{A}$ we prevent salt from reaching cells below $212.5 \mathrm{~cm}$ by preventing water movement to those cells. Although salt can move by dispersive flow, this movement is usually negligible. Advective flow contributes the most to salt leaching.

A variety of constraint equations can be used to prevent the salt content in lower cells from increasing. Here, an overachievement and underachievement constraint is utilized to prevent matric potential values in cells below $212.5 \mathrm{~cm}$ from increasing (becoming less negative). Overachievement values are minimized via the objective function $\left(w_{m}^{+}=1\right)$. This ensures that throughout the season no irrigation water will reach cells below $212.5 \mathrm{~cm}$ (no upward water movement can occur since all these cells have the same water content at the beginning of the season). Since it is unnecessary to minimize underachievement variables on matric potential, $w_{m}^{-}$is set to 0 in the objective function. If underachievement values are dif-

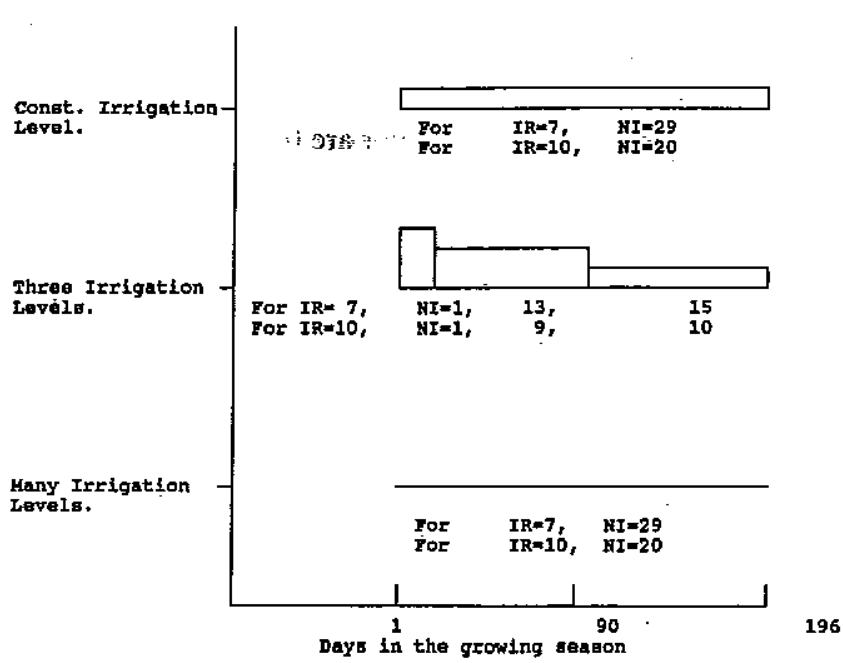

Figure 2. Irrigation schemes tested. IR, irrigation frequency; NI, number of irrigations for each frequency; Const., constant. 
ferent from 0 , the corresponding cells are drier than the target value (note that matric potential is negative).

A different sort of constraint can also be utilized to prevent salt concentration increase below $212.5 \mathrm{~cm}$. Depending on the initial conditions of the soil profile, a hard constraint on water flux or concentration could be utilized. However, model nonlinearity and solution time would increase.

Management approach B involves preventing salt concentration in the upper $112.5 \mathrm{~cm}$ (the root zone) from exceeding $160 \mathrm{meq} / \mathrm{L}$ at any time during the growing season but permits leaching. The $160-\mathrm{meq} / \mathrm{L}$ target concentration is based on a review by Ayers [1977] on crop tolerance to salinity of the saturated extract, as reported originally by Maas and Hoffman [1977]. Maintaining a root zone concentration of less than 160 meq/L and removing the no-leaching constraint allows the model to apply as much water as needed to maximize crop yield. Leaching of salt below the root zone and out of the profile is permitted even if it contaminates groundwater.

In the $\mathrm{S} / \mathrm{O}$ model, a value of $-10,500 \mathrm{~cm}$ is assumed for $C_{50}$. Cardon and Letey $[1992 \mathrm{a}, \mathrm{b}]$ reported a value of $-6500 \mathrm{~cm}$ for alfalfa based on compiled data on crop salt tolerance for alfalfa as reported by Maas [1986]. They found that it gave good results when compared with field data. Hanks and Cui [1991] reported a water potential value of $-15,000 \mathrm{~cm}$ when transpiration ceased. An intermediate $-10,500 \mathrm{~cm}$ value is used because the objective of this study is to demonstrate a methodology rather than to calculate an exact value of $C_{50}$.

For both approaches A and B, (15)-(21) and (26)-(30) are used. Equation (25) is used only for approach $A$, and (24) is used only for approach B. Since $R_{d p}$ equals $0,(22)$ and (23) are not used here. For approach $\mathrm{A}, w_{m}^{+}$equals 1 and $w_{m}^{-}, w_{c}^{+}$, and $w_{c}$ equal 0 , while $w_{c}^{+}$equals 1 and $w_{m}^{+}, w_{m}^{-}$, and $w_{c}^{-}$equal 0 for approach $\mathbf{B}$.

The model has approximately 8000 equations, which are solved simultaneously in time and space by using MINOS

Table 2. Initial Conditions, Showing Moisture Content and Salt Concentration Versus Depth at the Beginning of the Growing Season

\begin{tabular}{ccc}
$\begin{array}{c}\text { Cell } \\
\text { Number }\end{array}$ & $\begin{array}{c}\text { Water } \\
\text { Content, } \\
\text { by } \\
\text { volume }\end{array}$ & $\begin{array}{c}\text { Salt } \\
\text { Concentration, } \\
\text { meq/L }\end{array}$ \\
\hline 0 & 0.095 & 90 \\
1 & 0.095 & 90 \\
2 & 0.12 & 90 \\
3 & 0.15 & 90 \\
4 & 0.15 & 90 \\
5 & 0.15 & 93 \\
6 & 0.15 & 93 \\
7 & 0.15 & 93 \\
8 & 0.15 & 119 \\
9 & 0.15 & 119 \\
10 & 0.15 & 120 \\
11 & 0.15 & 120 \\
12 & 0.15 & 120 \\
13 & 0.15 & 106 \\
14 & 0.15 & 106 \\
15 & 0.15 & 106 \\
16 & 0.15 & 106 \\
17 & 0.15 & 86 \\
18 & 0.15 & 86 \\
19 & 0.15 & 74 \\
20 & 0.15 & 74 \\
21 & 0.15 & 74 \\
\hline
\end{tabular}
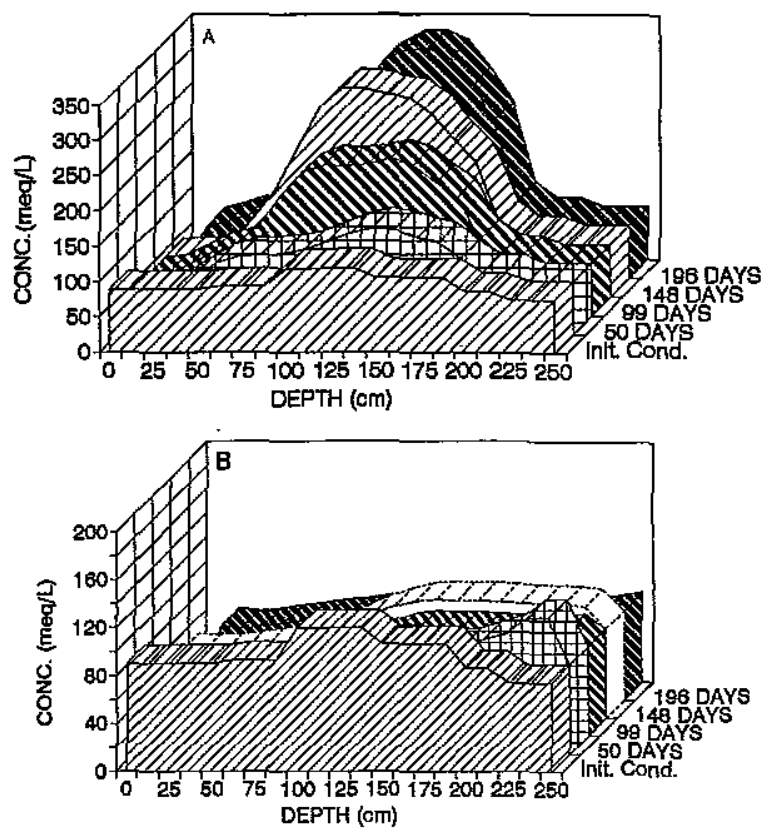

Figure 3. Salt distribution profile for many irrigation levels and 7-day irrigation interval for (a) approach $A$ and (b) approach B.

[Murtagh and Saunders, 1987]. Depending on the number of cycles, each model solution requires 2 to 6 hours to run on a VAX 6250, a Cray-Y/MP/832, or an IBM RS6000.

The difference in crop yields obtained from approaches $A$ and B illustrates the yield reduction necessary for groundwater protection.

\section{Results and Discussion}

The results of model application include optimal applied water and ratio of actual to potential transpiration, or percent yield, as represented in (1) (Tables $1 \mathrm{a}$ and $1 \mathrm{~b}$ ). Figures $3 \mathrm{a}$ and $3 \mathrm{~b}$ illustrate the salt distribution profiles for 7-day irrigation frequency and the third irrigation scheme for approaches $A$ and B, respectively. Figure 4 is analogous for a 10-day irrigation frequency.

Observations include the following. For both management approaches there is little difference in yield between 10-day and 7-day irrigation intervals. The more freedom in varying the irrigation amounts, the more crop yield. For the no-leaching approach $\mathrm{A}$, forcing all irrigations to be equal in magnitude produces the least yield. For the no-leaching approach $\mathrm{A}$, applied irrigation water exceeds transpiration by a small amount. Some water is stored in the root zone by the end of the season. Except for scenarios involving the constant irrigation scheme, the first irrigation amount is always the greatest. The top $25 \mathrm{~cm}$ (first two cells) is drier than the rest of the profile at the beginning of the season. More water is needed at the beginning of the season to fill the root zone to near field capacity. If leaching is permitted and the concentration in the root zone is restrained from exceeding $160 \mathrm{meq} / \mathrm{L}$, the model tends to apply more water, leach excess salt from the root zone, and increase crop transpiration. In this case applied water far exceeds the crop water requirement. The more flexibility in assigning irrigation amounts, the less water will be used and the more yield will be obtained for both approaches. The difference in crop 

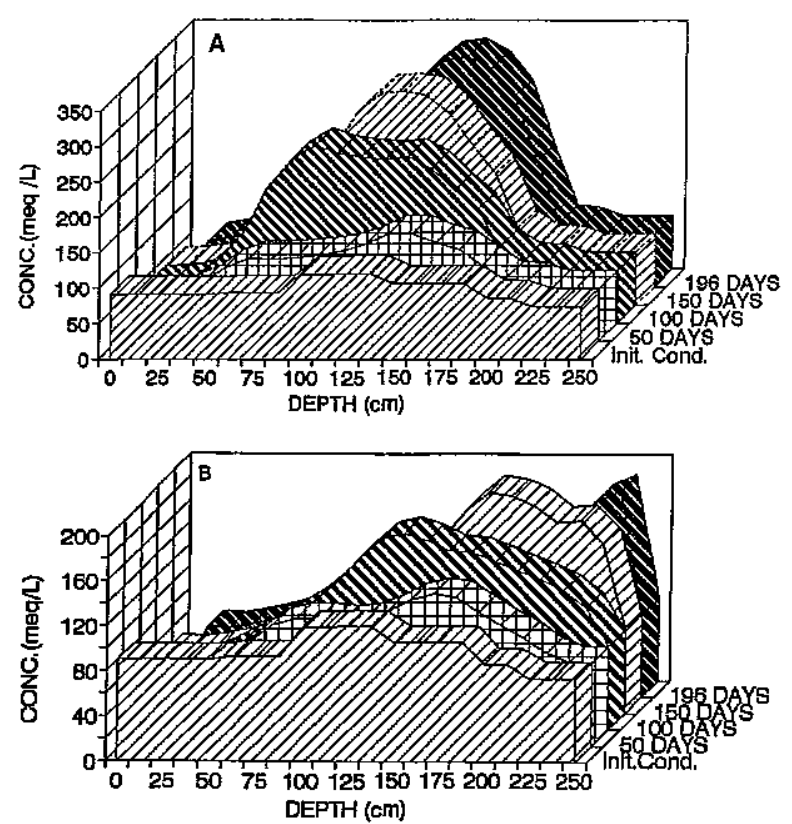

Figure 4. Salt distribution profile for many irrigation levels and 10-day irrigation interval for (a) approach $A$ and (b) approach B.

yield resulting from strategies which permit or do not permit leaching is the crop yield reduction needed to preserve groundwater quality (Table 3). For approach A, all added salt in irrigation water remained in the root zone. The salt content of the soil at the end of the growing season is higher than the initial content:

Optimal irrigation amounts computed for both approaches apply for only one irrigation season. The calculated optimal strategy is inappropriate for a second season. These strategies are based on initial and boundary conditions at the start of the season. Thus for a second season, different initial conditions are used and another optimal strategy should be computed.

The number of cycles required by the model to converge differs with the scenario. The more freedom there is to compute irrigation amount, the more cycles are needed. For both approaches $\mathrm{A}$ and $\mathrm{B}$, the most cycles were needed for the different irrigation amounts scheme, followed by the three irrigation amounts scheme and the constant irrigation amount scheme. For example, for approach $A$ and the different irrigation amounts scheme, the percent yield value reported in Table 1 was obtained within four cycles. Further cycling did not improve the objective function. For approach $\mathrm{A}$ and the three irrigation amounts scheme, three cycles were needed.

The calibration coefficients in modules $\mathrm{B}$ and $\mathrm{C}$ differ in value for every cell and time step (indexed $i, j$ ). In all cycles these coefficients remained within the specified bounds. The value of each coefficient could change with cycle. The magnitude of the change differed with the cell. Calibration coefficients changed more in cells with changing moisture content (due to irrigation, evapotranspiration, and/or root extractions) than in cells where moisture content did not change significantly.

This paper describes seasonal irrigation strategies that apply for the assumed initial and boundary conditions. To sustain crop yield over the long term, appropriate target water content and concentration profiles must be specified. Moreover, tested irrigation schemes (fixed irrigation amount scheme and the three irrigation amount scheme) and irrigation frequencies are physically, legally, and socially feasible and could be implemented in the field. Water rights in Utah permit irrigating on a fixed frequency or on demand, depending on the situation. The simulation model on which the S/O code is based has been verified and used for irrigation scheduling in Utah. The inputs to the simulation model are appropriate to satisfy social, legal, and physical constraints.

Since the model is nonlinear in the objective function and constraints, computed optimal solutions cannot be proven to be globally optimal. However, for each scenario the model was run several times, each time using a different set of initial guesses for the variables. The best optimal strategy (objective function) from all runs is reported. This strategy might be close to the global optimum.

\section{Sensitivity to Potential Evapotranspiration}

Sensitivity analysis is performed to evaluate the effect of changes in potential evapotranspiration on the results of optimal strategy implementation. The optimal strategy developed for 7-day irrigation frequency, three irrigation levels, and the no-leaching approach $\mathrm{A}$ is used.

The response of the system to $5 \%, 10 \%, 15 \%$, and $20 \%$ increases and decreases in daily $E T^{p}$ is analyzed. Increasing $E T^{p}$ by $5 \%$ to $20 \%$ decreased yield but did not increase salt movement to lower cells. Yield decrease results from applying less water than needed by the crop. Increases in $E T^{p}$ of $5 \%$ to $10 \%$ cause acceptable yield reduction. Increases in $E T^{p}$ of $15 \%$ and $20 \%$ reduce yield from $80 \%$ of potential yield to $74.2 \%$ and $72.7 \%$, respectively. For such climatic conditions a different optimal strategy should be computed and used.

Decreasing $E T^{p}$ increases crop yield. Depending on the magnitude of this decrease, salt might move to lower cells. For a $5 \% E T^{p}$ decrease, no significant effect on salt distribution and yield is observed. At a $10 \%$ to $15 \%$ decrease in $E T^{p}$, salt reaches lower cells but does not leave the profile. For a $20 \%$ $E T^{p}$ decrease, salt leached out of the profile: For $15 \%$ and $20 \% E T^{p}$ reductions, yield increased to $86.9 \%$ and $88 \%$ of potential crop yield, respēctively.

In summiary, the optimal solution is valid for any increase or decrease in $E T^{p}$ up to $10 \%$. For greater changes in $E T^{p}$, new optimal strategies should be computed.

\section{Conclusion}

A nonlinear S/O model that maximizes crop yield and prevents groundwater contamination is developed. The model

Table 3. Computed Yields for Approach A and Approach $B$, and the Difference in Yield Between the Two Approaches

\begin{tabular}{|c|c|c|c|}
\hline \multirow[b]{3}{*}{ Approach } & \multicolumn{3}{|c|}{ Yield, \% } \\
\hline & \multicolumn{2}{|c|}{ 7-Day Interval } & \multirow[b]{2}{*}{$\begin{array}{c}\text { 10-Day Interval, } \\
\text { Many Irrigation } \\
\text { Levels }\end{array}$} \\
\hline & $\begin{array}{l}\text { Three } \\
\text { Irrigation } \\
\text { Levels }\end{array}$ & $\begin{array}{l}\text { Many } \\
\text { Irrigation } \\
\text { Levels }\end{array}$ & \\
\hline A (no leaching permitted) & 80.3 & 81.7 & 79.8 \\
\hline B (leaching permitted) & 93 & 93.2 & 93.4 \\
\hline Difference in yield, \% & 12.7 & 11.5 & 13.6 \\
\hline
\end{tabular}


incorporates the finite difference forms of the water flow equation (Richards' equation [Richards, 1931]) and the convectiondispersion equation as constraints. It employs a MODCONtype approach for solving nonlinear optimization problems having embedded constraints. The S/O model successfully considers flow dynamics in the unsaturated zone in detail without errors caused by coarse discretization in time. The model is potentially valuable for irrigation management in areas where salty water is used for irrigation.

Acknowledgments. This work was supported by the USDA/CSRS Groundwater Quality Program, the Utah Agricultural Experiment Station, and the Departments of Biological and Irrigation Engineering and Plants, Soils, and Biometeorology, Utah State University, Logan, Utah. Approved as journal paper 4586.

\section{References}

Ahlfeld, D. P., J. M. Mulvey, and G. F. Pinder, Designing optimal strategies for contaminated groundwater remediation, Adv. Water Resour., 9(2), 77-84, 1986.

Alley, W. M., Regression approximations for transport model constraint sets in combined aquifer simulation-optimization studies, Water Resour. Res., 22(4), 581-586, 1986.

Atwood, D. F., and S. M. Gorelick, Hydraulic gradient control for groundwater contaminant removal, J. Hydrol., 76, 85-106, 1985.

Ayers, S. R., Quality of water for irrigation, J. Irig. Drain. Div. Am. Soc. Civ. Eng., 103(IR2), 136-154, 1977.

Bingham, G. E., E. Malek, G. D. McCurdy, and R. J. Hanks, Irrigation season water balance at the Hunter and Huntington Farms, part 2 , Res. Rep. 122, Utah Agric. Exp. Stn., Logan, 1988.

Bingham, G. E., E. Malek, G. D. McCurdy, and R. J. Hanks, Irrigation season water balance at the Hunter and Huntington Farms, part 2, Res. Rep. 128, Utah Agric. Exp. Stn., Logan, 1989.

Bingham, G. E., E. Malek, G. D. McCurdy, and R. J. Hanks, Irrigation season water balance at the Hunter and Huntington Farms, part 2 , Res. Rep. 133, Utah Agric. Exp. Stn., Logan, 1990.

Bowen, R. L., and R. A. Young, Financial and economic irrigation net benefit functions for Egypt's northern delta, Water Resour. Res., 21(9), 1329-1335, 1985.

Braester, C., Moisture variation at the soil surface and the advance of the wetting front during infiltration, Water Resour. Res., 9(3), 687$694,1973$.

Bresler, E., Simultaneous transport of solutes and water under transient unsaturated flow conditions, Water Resour. Res., 9(4), 975-985, 1973.

Bresler, E., and R. J. Hanks, Numerical method for estimating simultaneous flow of water and salt in unsaturated soils, Soil Sci. Soc. Am. Proc., 33, 827-832, 1969.

Bresler, E. B., L. McNeal, and D. L. Carter, Saline and Sodic Soils, Springer-Verlag, New York, 1982.

Brooks, R. H., and A. T. Corey, Hydraulic properties of porous media, Hydrol. Pap. 3, pp. 1-27, Colo. State Univ., Ft. Collins, Colo., 1964.

Campbell, G. S., A simple method for determining unsaturated conductivity from moisture retention data, Soil Sci., 117, 311-314, 1974.

Cardon, G. E., and J. Letey, Soil-based irrigation and salinity management model, I, Plant water uptake calculations, Soil Sci. Soc. Am. J., 56(6), 1881-1887, 1992a.

Cardon, G. E., and J. Letey, Soil-based irrigation and salinity management model, II, Water and solute movement calculations, Soil Sci. Soc. Am. J., 56(6), 1887-1898, $1992 \mathrm{~b}$.

Childs, S. W., and R. J. Hanks, Model of soil salinity effects on crop growth, Soil Sci. Soc. Am. Proc., 39(4), 617-622, 1975.

Colarullo, S. J., M. Heidari, and T. Maddock III, Identification of an optimal groundwater management strategy in a contaminated aquifer, Water Resour. Bull, 20(5), 747-760, 1984.

Datta, B., and R. C. Peralta, Optimal modification of regional potentiometric surface design for groundwater contaminant protection, Trans. ASAE, 29(4), 1611-1623, 1986.

De Wit, C. T., Transpiration and Crop Yields, Institute of Biological and Chemical Research on Field Crops and Herbage, Wageningen, Netherlands, 1958.
Doorenbos, J., and A. H. Kassam, Yield response to water, FAO Inig. Drain. Pap., 33, 1979.

Dudley, L. M., R. J. Hanks, W. R. Mace, and R. L. Cartee, Use of saline waste water from electrical power plants for irrigation, 1, Soil, irrigation water and crop yield, Res. Rep. 137, Utah Agric. Exp. Stn., Logan, 1991.

Feddes, R. A., E. Bresler, and S. P. Neuman, Field test of a modified numerical model for water uptake by root systems, Water Resour. Res., 10(6), 1199-1206, 1974.

Feddes, R. A., P. J. Kowalik, and H. Zaradny, Simulation of Field Water Use and Crop Yield, 188 pp., John Wiley, New York, 1978.

Gharbi, A., and R. C. Peralta, Integrated embedding optimization applied to Salt Lake Valley aquifers, Water Resour. Res., 30(3), 817-832, 1994.

Gorelick, S. M., A review of distributed parameters groundwater management modeling methods, Water Resour. Res., 19(2), 305-319, 1983.

Gorelick, S. M., C. I. Voss, P. E. Gill, W. Murray, M. A. Saunders, and M. H. Wright, Aquifer reclamation design: The use of contaminant transport simulation combined with nonlinear programming, Water Resour. Res., 20(4), 415-427, 1984.

Hanks, R. J., Yield and water-use relationships: An overview, in Limitation to Efficient Water Use in Crop Production, edited by $\mathrm{H}$. M. Taylor, W. R. Jordan, and T. R. Sinclair, pp. 393-411, American Society of Agronomy, Madison, Wis., 1983.

Hanks, R. J., and J. K. Cui, Manual for Using SOWATSAL, Soil-PlantAtmosphere-Salinity Management Model, Utah State Univ., Logan, 1991.

Hanks, J. R., A. Klute, and E. Bresler, A numeric method for estimating infiltration, redistribution, drainage, and evaporation of water from soil, Water Resour. Res., 5(5), 1064-1069, 1969.

Heidari, M., J. Sadeghipour, and O. Drici, Velocity control as a tool for optimal plume contaminant in Equus Beds aquifer, Kansas, Water Resour. Bull., 23(2), 325-335, 1982.

Hutson, J. L., and A. Cass, A retentivity function for use in soil-water simulation models, J. Soil Sci., 38, 105-133, 1987.

Khan, A. I., Managing salinity in irrigated agriculture, J. Imig. Drain., 108(IR1), 43-56, 1982.

Lefkoff, L. J., and S. M. Gorelick, Simulating physical processes and economic behavior in saline, irrigated agriculture: Model development, Water Resour. Res., 26(7), 1359-1369, 1990.

Maas, E. V., Salt tolerance of plants, Appl. Agric. Res., 1(1), 12-26, 1986.

Maas, E. V., and G. J. Hoffman, Crop salt tolerance-current assessment, J. Irig. Drain. Div. Am. Soc. Civ. Eng., 103(IR2), 115-134, 1977.

Malek, E., C. E. Bingham, G. D. McCurdy, and R. J. Hanks, Irrigation season water balance at the Hunter and Huntington Farms, part 2, Res. Rep. 137, Utah Agric. Exp. Stn., Logan, 1991.

Matanga, B. G., and M. A. Marino, Irrigation planning, 2, Water allocation for leaching and irrigation purposes, Water Resour. Res., 15(3), 679-683, 1979.

Molz, F. J., Models of water transport in the soil-plant system: A review, Water Resour. Res., 17(5), 1245-1260, 1981.

Molz, F. J., and L. C. Bell, Head gradient control in aquifers used for fluid storage, Water Resour. Res., 13(4), 795-798, 1977.

Murtagh, B. A., and M. A. Saunders, MINOS 5.1 user's guide, Rep. SOL 83-20R, Stanford Univ., Stanford, Calif., December 1983, revised January 1987.

Musharrafieh, G., Optimizing irrigation management for pollution control and sustainable crop yield, Ph.D. dissertation, 127 pp., Utah State Univ., Logan, 1993.

Neuman, S. P., R. A. Feddes, and E. Bresler, Finite element analysis of two-dimensional flow in soils considering water uptake by roots, $I_{2}$ Theory, Soil Sci. Soc. Am. J., 39, 224-230, 1975.

Nimah, M. N., and R. J. Hanks, Model for estimating soil water and atmospheric interactions: Description and sensitivity, Soil Sci. Soc. Am. Proc., 37(4), 522-527, 1973.

Peralta, R. C., and P. J. Killian, Optimal regional potentiometric surface design: Least cost supply/sustained groundwater yield, Trans. $A S A E, 28(4), 1098-1107,1985$.

Peralta, R. C., and R. Ward, Short-term plume containment: Multiobjective comparison, Ground Water, 29(4), 526-535, 1991.

Peralta, R. C., K. Kowalski, and R. R. A. Cantiller, Maximizing reliable crop production in a dynamic stream/aquifer system, Trans. $A S A E$, $31(6), 1729-1742,1988 \mathrm{a}$. 
Peralta, R. C., J. Solaimanian, and C. L. Griffis, Development of a combined quality and quantity model for optimal unsteady groundwater management, Proj. Completion Rep. IIC-88/3, 43 pp., Arkansas Water Resour. Res. Cent., Univ. of Arkansas, Fayetteville, and Int. Irrig. Cent., Utah State Univ., Logan, 1988b.

Peralta, R. C., A. Gharbi, L. S. Willardson, and A. Peralta, Optimal conjunctive use of ground and surface waters, in Management of On Farm Imigation Systems, edited by G. Hoffman, T. Howell, and K. Solomon, pp. 426-458, American Society of Agricultural Engineers, St. Joseph, Mich., 1990.

Remson, I., and S. M. Gorelick, Management models incorporating groundwater variables, in Operation Research in Agricultural and Water Resources, edited by D. Yaron and C. Tapiero, pp. 333-356, North-Holland, New York, 1980.

Richards, L. A., Capillary conduction of liquids through porous mediums, Physics, 1, 318-333, 1931.

Ross, J. P., Efficient numerical methods for infiltration using Richards' equation, Water Resour. Res., 26(2), 279-290, 1990.

Ross, J. P., and K. L. Bristow, Simulating water movement in layered and gradational soils using the Kirchoff transform, Soil Sci. Soc. Am. J., 54, 1519-1924, 1990.

U.S. Salinity Laboratory Staff, Diagnosis and improvement of saline and alkaline soils, Agric. Handb. 60, p. 160, U.S. Dep. of Agric., Washington, D. C., 1954.

van Genuchten, M. T., A numerical model for water and solute movement in and below the root zone, Res. Rep. 121, U.S. Dep. of Agric. Agric. Res. Stn., U.S. Salinity Lab, Riverside, Calif., 1987.

van Genuchten, M. T., and D. R, Nielsen, $O_{n}$ describing and predicting the hydraulic properties of unsaturated soils, Ann. Geophys., $3(5), 615-628,1985$.

Willis, R., A planning model for management of groundwater quality, Water Resour. Res., 15(6), 1305-1312, 1979.

Willis, R., and W. W. G. Yeh, Ground Water System Planning and Management, Prentice-Hall, Englewood Cliffs, N. J., 1987.

Yaron, D., and B. Harpinist, A model for optimal irrigation scheduling with saline water, Water Resour, Res., 16(2), 257-262, 1980.

G. R. Musharrafieh and R. C. Peralta, Department of Biological and Irrigation Engineering, Utah State University, Logan, UT 84322-4104.

L. M. Dudley and R. J. Hanks, Department of Plants, Soils, and Biometeorology, Utah State University, Logan, UT 84322-4820.

(Received July 5, 1994; revised November 1, 1994; accepted November 2, 1994.) 